DOI: $10.17805 /$ ggz.2019.6.4

\title{
К вопросу о внешности Тамерлана: биографические источники и их интерпретация в пьесах К. Марло*
}

\author{
Н. В. Шипилова
}

Православный Свято-Тихоновский гуманитарный университет, г. Москва

В статье рассматриваются основные биографические источники сведений о Тимуре, к которым мог обращаться Кристофер Марло при работе над пьесой «Тамерлан» и которые повлияли на создание образа протагониста, в особенности его внешности. Хотя более аутентичные восточные источники не были известны в Европе в переводах до XVII в., Марло был доступен довольно широкий набор европейских исторических текстов (Халкокондил, Боден, Мехиа, Фрегозо, Бициарри и др.). Подробное описание внешности Тамерлана было известно Марло по трактату Пьетро Перондини «Жизнь Тамерлана Великого, императора скифов». В статье проводится сопоставление поэтического текста Марло с описанием Перондини, что позволяет продемонстрировать, какие ключевые характеристики Марло непосредственно заимствует у историка (рост, физическая сила, взгляд), а какие представляют собой более сложное соединение нескольких традиции.

Ключевые слова: К. Марло; «Тамерлан»; литература раннего Нового времени; елизаветинская драматургия; П. Перондини

\section{Tamburlaine's Appearance Revisited: Christopher Marlowe's Interpre- tation of Biographical Sources}

N. V. Shipilova, St. Tikhon's Orthodox University, Moscow

The article addresses the main biographical sources of information about Amir Timur (Tamerlane) which were available to Christopher Marlowe during his work on the drama of Tamburlaine and could influence the image of his protagonist, focusing on his appearance. Although authentic Oriental sources were not translated into European languages until the 17th century, Marlowe was able to

\footnotetext{
* Статья подготовлена в рамках проекта «Кристофер Марло и его творчество в русской и мировой культуре: междисциплинарный взгляд» при финансовой поддержке Российского фонда фундаментальных исследований (грант № 18-012-00679).

The article was prepared within the framework of the project "Christopher Marlowe and His Literary Heritage in Russian and World Culture: An Interdisciplinary Look" with financial support from the Russian Foundation for Basic Research (grant No. 18-012-00679).
} 
use a fairly wide range of European historical texts (Chalcondyles, Bodin, Fregoso, Bizzarri, and others.) A detailed description of Tamerlane's appearance was available to Marlowe through Pietro Perondini's “Magni Tamerlanis Scytharum imperatoris vita" ("Life of Tamburlaine the Great, Emperor of the Scythians"). The author compares Marlowe's poetic text with Perondini's portrait of Tamerlane, which allows us to demonstrate which key characteristics were directly borrowed from the historian (such as height, physical strength, eyes) and which represent a more complex combination of several traditions.

Keywords: C. Marlowe; "Tamburlaine”, early modern literature; Elizabethan theatre; P. Perondini

\section{ВВЕДЕНИЕ}

Одной из задач изучения «Тамерлана» Кристофера Марло на протяжении последних полутора веков является, несомненно, попытка установить источники, послужившие драматургу опорой и отчасти вдохновением при создании пьесы. Хотя «Тамерлан», разумеется, полностью художественное произведение, значительная часть описанных в тексте военных кампаний вымышлена, а исторические сведения искажены ради общего замысла текста или драматического эффекта, невозможно отрицать, что Марло широко использовал вполне конкретные данные по истории и географии. Если источник его сведений по географии установлен с достаточной точностью - это атлас Авраама (Абрахама) Ортелия 1570 г. «Зрелище круга земного», что было впервые продемонстрировано Э. Ситон в работе «Карта Марло» в 1924 г. (Seaton, 1924), то в случае с историческими источниками это сделать труднее: биографических повествований о судьбе Амира Тимура в ренессансной Европе было достаточно много, в том числе и тех, которые могли быть доступны Марло. Для установления связи между источником и пьесой текст «Тамерлана» сопоставлялся с теми или иными эпизодами исторических трактатов.

Само предположение о том, что основным источником для Марло являлось английское издание «Сборника различных наставлений» Педро Мехиа, было выдвинуто Ч. Х. Херфордом и А. Вагнером еще в 1883 г. (Herford, Wagner, 1883); затем влияние Мехиа подробно рассматривал Л. Спенс (Spence, 1926). В 1930 г. в комментированном издании «Тамерлана» У. Эллис-Фермор в приложениях привела выдержки из исторических источников, однако издание, которое наконец воспроизвело их полностью под одной обложкой, появилось только полвека спустя - «Кристофер Марло: пьесы и их источники» В. Томас и У. Тидемана (Thomas, Tydeman, 1994). 
Настоящая статья ставит своей задачей рассмотреть в общих чертах основные биографические источники о жизни Амира Тимура и их влияние на текст пьесы Марло, особенно в вопросе изображения внешности героя. Для удобства разграничения исторический персонаж в статье называется Тимуром, персонаж пьесы Марло и европейской литературы раннего Нового времени - Тамерланом.

\section{ВОСТОЧНЫЕ И ЕВРОПЕЙСКИЕ ИСТОЧНИКИ О БИОГРАФИИ ТИМУРА}

Хотя сохранившиеся воспоминания Тимура учеными сейчас, как правило, считаются поддельными, существует ряд восточных летописей, которые могут служить достаточно надежным источником сведений о биографии полководца. Низам ад-Дин Шами стал официальным летописцем Тимура после падения Багдада в 1393 г., когда присягнул завоевателю. Заслужив впоследствии доверие государя, он получил задание вести официальные летописи, сделавшись, таким образом, единственным хронистом, работавшим при жизни Тимура (Froggatt, 1962: 329). Низам ад-Дин использовал как записи секретарей, так, вероятно, и фрагменты воспоминаний самого Тимура. Его «Зафар-наме» («Книга побед»), написанная на фарси между 1400 и 1404 гг., стала основой для многих последующих жизнеописаний.

Другие важнейшие тексты восточных историков XIV в. - хроника «Зафар-наме» Шарафа ад-Дина Язди, написанная в 1419-1425 гг. при дворе сына Тимура Шахруха и заметно идеализирующая полководца, и «История Тимура» арабского историка Ахмеда Ибн Арабшаха, законченная в 1435 г. в Дамаске и представляющая противоположный, крайне враждебный взгляд на Тимура. Существует также отчет Альхазена, якобы современника Тимура и участника его походов, источник довольно спорный и, возможно, не аутентичный, но заслуживающий упоминания из-за своей крайней популярности в Европе.

Ренессансной Европе восточные хроники известны не были. Произведение Альхазена, вызвавшее своего рода «моду на Тамерлана» у многих авторов XVII в. (Andrea, 2010: 46), было переведено на английский язык уже в 1625 г., но «Тамерлан» Марло написан раньше этой даты. «История Тимура» Ибн-Арабшаха была переведена на французский язык ориенталистом Пьером Ватье только в 1658 г.; другие тексты появились на европейских языках намного позже (Дадабоев, 2013: 37).

Среди ранних европейских источников нужно в первую очередь отметить «Дневник путешествия в Самарканд ко двору Тимура (1403-1406)» Руи Гонсалеса де Клавихо. Камергер короля Кастилии и Леона Энрике III Болез- 
ненного, Гонсалес де Клавихо возглавил посольство в Самарканд. Путешествие заняло долгих три года, в течение которых испанский дипломат вел подробный дневник, описывая обычаи чужой культуры, - после Марко Поло такие заметки сделались популярны в Европе (Литус, 2014: 262). Хотя из-за смерти Тимура дипломатические отношения так и не были установлены, дневник Гонсалеса де Клавихо остался источником ценных сведений об империи Тимура.

Он содержит, в частности, и краткое описание наружности Тимура, оставленное непосредственным очевидцем: «Сеньор восседал на шелковой расшитой маленькой подстилке, а локоть его покоился на круглой подушечке. Он был одет в гладкое шелковое платье без рисунка, на голове носил высокую белую шапку с рубином наверху, с жемчугом и драгоценными камнями. Как только посланники увидели его, поклонились... <..> А сеньор сказал, чтобы они подошли [еще] ближе для того, чтобы рассмотреть их хорошенько, так как он плохо видел из-за старости и почти не мог поднять веки» (Гонсалес де Клавихо, 1990: 108-109).

Список европейских источников, которые в том или ином виде могли быть доступны Марло, достаточно обширен. Степень их достоверности сильно разнится, хотя все они, безусловно, имеют определенную историческую базу. У. Эллис-Фермор при составлении списка источников руководствовалась отдельными сюжетными мотивами, которые встречаются у Марло и могут быть возведены к конкретному источнику, особенно теми, которые встречаются только у одного из историков и таким образом доказывают, что Марло опирался именно на него (Ellis-Fermor, 1951: 86).

Так, византийский историк Лаоник (Николай) Халкокондил (ок. 1423/30-1490), автор десятикнижия «Истории», изданного на латыни в Базеле в 1556 г., упоминает о необыкновенном уважении и привязанности Тимура к своей главной жене, которая могла являться отдаленным прообразом Зенократы. Рассказ Халкокондила намного ближе к исторической реальности; по сравнению с позднейшими историками он хорошо представляет разницу между европейским правителем и восточным ханом и не европеизирует Тимура. Жена Тимура в его «Историях» напоминает реальную Сарай-мульк ханым, вдову из рода Чингизидов, брак с которой принес Тимуру статус и почетный титул «зять хана». Сарай-мульк ханым пользовалась колоссальным авторитетом при дворе супруга, даже несмотря на то, что не родила ему детей. Хотя дочь египетского султана Зенократа вымышлена, а поэтический накал любви Тамерлана к ней, безусловно, - творение Марло, фрагмент из Халкокондила предположительно мог стать отдаленным источником вдохновения. 
Другой пример использования конкретного источника впервые привел X. Дж. Дик (Dick, 1949: 154). Большинство европейских источников изображают турецкого султана Баязида с явной симпатией, как правило, в противовес Тимуру, у Марло же Баязид почти лишен достоинства, отваги и вообще каких-либо привлекательных черт. Хотя это, конечно, отчасти обусловлено сценическими требованиями, необходимостью сконцентрировать внимание публики на протагонисте пьесы, Дик предполагает, что идею противопоставления Тамерлана и Баязида Марло мог почерпнуть у французского политика и философа Жана Бодена. Боден был при елизаветинском дворе в 1581 г. в свите герцога Алансонского; его известнейший трактат «Шесть книг о государстве» широко обсуждался в Кембридже (как раз во время учебы Марло) и стал пользоваться такой популярностью, что Боден в 1586 г. сам перевел его на латынь.

Боден описывает поход Тимура против Баязида как выступление с целью свержения тирана, «чтобы покарать его тиранию и освободить страдающий народ» (пер. мой. - H. Ш.; “to chastice his tiranie, and to deliuer the aflicted people...”; Bodin, 1606: 221), т. е. как поход за правое дело.

Ричард Ноллс, один из первых английских историков-востоковедов, переводил Бодена на английский — правда, уже в начале XVII в. В 1603 г. вышла главная работа самого Ноллса — «Общая история турков» (“The Generall Historie of the Turkes”). Дик предполагает, что Марло мог быть знаком с Ноллсом через семейство Мэнвуд и даже, возможно, иметь доступ к его работам задолго до публикации, как и к другим историческим текстам из библиотеки Мэнвудов, чем объясняется его превосходное знание источников (Dick, 1949: 164-166).

Среди прочих авторов, на которых в поиске общих исторических сведений о Востоке предположительно опирался Марло, могут быть названы француз Пьер де ла Примоде («Французская академия», 1577; переведена на английский в 1586 г.), армянин Хетум Патмич, также известный как ХетумИсторик и Хайтон («Цветник историй земель Востока», 1307; по повелению папы Климента V текст был записан на старофранцузском, а затем переведен на латынь, есть французский перевод ок. 1501 г.), писавшие на латыни итальянцы Баптиста Фрегозо («О достопамятных изречениях и деяниях», 1518) и Пьетро Биццарри (Петрус Бизарус; «Персидская история», 1583).

Однако главными историческими источниками непосредственно по биографии Тимура для Марло послужили латинский трактат флорентийца Пьетро Перондини «Жизнь Тамерлана Великого, императора скифов» (1553) и «Сборник различных наставлений» испанца Педро Мехиа (1544) в сокра- 
щенном и местами неточном английском переводе Томаса Фортескью (1571, второе издание 1576).

\section{ВНЕШНИЙ ОБЛИК ГЕРОЯ}

Что касается внешности героя, ее наиболее подробное описание находим у Перондини. Его трактат удобно поделен на небольшие главы, каждая из которых посвящена определенной теме или эпизоду из биографии. Глава 21 содержит описание наружности Тамерлана:

"Statura fuit procera et eminenti, barbatus, latus ab humerus et pectore, caeterisque membris aequalis et congruens integra valetudine, excepto altero pede, quo non perinde valebat, ut inde claudicare ac deformiter incedere propiceretur, oris truculenti atque obductae suae frontis oculi introrsus recedentes praeferocis animi sui saeuitiem spirantes intuentibus terrorem et firmidinem incutiebant, valida erat usque adeo neruorum compage, ut validissimum quemque e Scythia in palestra prosterneret, ac Parthici ingentis arcus chordam lacertosis brachiis ultra aurem facile posset extendere, aenumque mortarium excussi iaculi spiculo transfodere" (Perondino, 1600: 56-57).

«Был он высок ростом и худощав, бородат, широк в груди и плечах, все части его тела были соразмерными и здоровыми, кроме одной ноги, которая была не такой сильной, как другая, потому он заметно хромал и ходил неуклюже. Его глубоко посаженные глаза, придававшие жестокий вид лицу, и хмурое чело, выражавшее ярость надменного духа, повергали в ужас и трепет в тех, кто видел его. Телосложение его было настолько могучим и развитым, что на площадке для рукопашного боя он повергал наземь сильнейших из скифов, а своими мускулистыми руками мог натянуть тетиву огромного парфянского лука далеко за ухо, и, выпустив так стрелу, пронзить ею переднюю часть медного шлема» (пер. мой. - Н. Ш.).

Сопоставление этого фрагмента с тем, как описан Тамерлан в начале второго акта пьесы (II, 1, 7-30), позволяет проследить, что именно Марло заимствует из биографической информации Перондини, а что отвергает как неподходящее для общего замысла.

Высокий для монгола рост и необыкновенная физическая сила Тимура отмечены многими историками: рост - это первое, что упоминает, например, Ибн-Арабшах (Froggatt, 1962: 330), то же делает и Перондини, и, вслед за ним, Марло. Рассказ Менафона у Марло начинается фактически теми же словами, что отчет Перондини: “Of stature tall, and straightly fashioned..." (Marlowe, 1951: 92). Как и в трактате, герой исключительно силен и широк в 
плечах, хотя уподобление Тамерлана титану Атланту, держащему на плечах весь небесный свод, уже полностью принадлежит Марло, как и дальнейшее сравнение головы Тамерлана с перлом. Эта метафора поражает своей необычностью и неожиданной разницей масштаба по сравнению с могучим телом; ничего подобного у историка уже, конечно, не могло встретиться.

Другой аспект, тоже связанный с физической силой и похожий на то, что мы видим у Перондини, - упоминание могучих жилистых рук Тамерлана:

...His arms and fingers long and sinewy,

Betokening valour and excess of strength...

(II, 1; ibid.: 27-28)

Марло не упоминает такой важный для историка эпизод, как способность натянуть тяжелый парфянский лук дальше, чем способен обыкновенный воин. Возможно, это следствие того, что Марло в принципе не представлял центрального места лука как оружия для армии Тимура, его Тамерлан обычно пользуется коротким мечом. Метафора, связанная со стрельбой из лука, в пьесе есть, но вложена в уста труса Микета, который сравнивает царя, на которого ведется охота, с мишенью, используя характерную терминологию.

Сама сила рук, тем не менее, упомянута в пьесе. Прилагательное "sinеwy” («мускулистый, жилистый») в изданиях октаво 1590 и 1592 гг. выглядит как “snowy” («белоснежный»), но большинство современных редакторов считают это слово искажением и восстанавливают его в форму “sinewy". Дж. Каттс полагал, что каламбур замышлялся Марло изначально и слово предполагает двойное прочтение (Cutts, 1967: 106).

Актер труппы лорда-адмирала Эдвард Аллейн, сыгравший роль Тамерлана во время первой постановки в сезоне 1587-1588 гг., также отличался исполинским ростом, силой и громовым голосом и на небольшой сцене, просто раскинув руки, зрителям действительно казался великаном, способным потрясать мир (Cerasano, 1994: 179).

Отчасти схожи с вариантом Перондини у Марло описание лица, выдающего надменность и воинственность духа, и суровости глаз. Хотя если в последнем случае Перондини делает акцент на более конкретной физической характеристике («глубоко посаженные»), то Марло прибегает к сложной астрономической метафоре: пылающие глаза Тамерлана фактически вбирают все мироздание, целиком заключая в себе ренессансный космос с небесными телами в их сферах. Но впечатление исключительности и яростные страсти, 
отразившиеся в облике полководца, в целом схожи; различие здесь в первую очередь в стиле исторического и поэтического повествования.

Принципиальны другие отличия - физические характеристики, которые Марло намеренно исключает из своего описания. Это, во-первых, упоминание характерной для Востока бороды, которое есть и у Перондини, и у других биографов. Во-вторых, изъятие главнейшей физической характеристики Тимура - его хромоты.

Ранение в ногу было получено Тимуром скорее всего в юности, при неизвестных до конца обстоятельствах. По наиболее распространенной легенде, это была кара за грабежи: его ранил либо пастух, у которого он из-за нужды в семье украл барана, либо жители местности, где молодой Тимур с отрядом в пятьсот человек промышлял разбоем; эта могла быть как рана от стрелы, так и следствие перелома. Еще одна версия сообщает, что Тимур, погнавшись за кроликом, нечаянно напугал задремавшего отца, и тот случайно рассек ему ногу. Увечье могло быть и врожденным - антропологи предположили костный туберкулез (Мелехин, 2019: 18-22).

Так или иначе, хромота Тимура была исторически превосходно известна. Само его прозвище «ленг», из которого впоследствии образовалось имя Тимур-ленг, превратившееся в Европе в «Тамерлан», означает «хромец». По преданию, он оковал увечную ногу железом (так, например, рассказывается в древнерусской «Повести о Темир-Аксаке»). Перондини не сообщает таких впечатляющих подробностей, а приводит вполне реалистичное описание хромоты.

Марло же исключает любую возможность увечья, болезни или старой раны - физическое совершенство его героя абсолютно в соответствии с платоновским представлением о гармоническом сочетании физических и духовных характеристик человека. Характерно, что во второй части пьесы Тамерлан говорит сыновьям, что за всю жизнь не получил ни одного ранения и не пролил ни капли крови.

Если Перондини сравнивает властные и внушающие трепет черты в облике Тамерлана с характеристиками другого великого полководца, карфагенянина Ганнибала, то Марло последовательно сопоставляет его с античными богами и героями. Это в первую очередь Юпитер, о котором сам Тамерлан последовательно вспоминает, говоря о своей судьбе. Во фрагменте с описанием внешности это уже упоминавшийся Атлант и, главным образом, Ахилл. С образом Ахилла связано и еще принципиальное изменение - неестественно светлый цвет волос Тамерлана, описанный у Марло как “amber”, «янтарный» (по-видимому, рыжеватый или рыже-каштановый; само прилагательное в эпоху Ренессанса означало чуть более темный оттенок, чем в со- 
временном английском). В русском переводе «Тамерлана» Э. Л. Линецкой этот оттенок передан как «огненные пряди» (Марло, 1961a: 62).

Параллель с Ахиллом задана уже самим Марло: он прямо называет Тамерлана «яростным, как Ахилл» (“...as fierce Achilles’ was...”; Marlowe, 1951: 98; в рус. пер.: «...Как у могучего Ахилла...»; Марло, 1961а: 62), а рыжие и вьющиеся кудрями волосы усиливают сопоставление с античным героем. В «Илиаде» дважды упомянуты светлые волосы Ахилла, в классическом русском переводе Н. И. Гнедича названные «русыми»: «...Афина, / Став за хребтом, ухватила за русые кудри Пелида...» (Гомер, 1993: 20); «Став при костре, у себя он обрезал русые кудри...» (там же: 359). Нельзя утверждать наверняка, какой именно цвет имелся в виду у Гомера, так как греческое прилагательное “xanthos” может обозначать различные цвета от желтого до кирпичного, но, во всяком случае, это достаточно светлый оттенок.

Когда Фетида укрыла Ахилла перед началом Троянской войны на острове Скирос у царя Ликомеда, переодев сына в женское платье, то как дева Ахилл носил прозвание Пирра, «Пылающая», также по цвету волос. В «Ахиллеиде» Стация о герое говорится: «...И опоясал виски золотые пурпурной повязкой...» (Стаций, 2011: 75). Там же упоминается и белоснежное лицо Ахилла, красотой превосходившего прекрасных дев (там же: 33). В «Эпиталамии Ахилла и Дейдамеи» Биона переодетый Ахилл неотличим от дев Ликомеда:

...рукою

Белой он нитку тянул; имел он весь девичий облик:

Все было женственно в нем, и на белых щеках расцветали

Алые так же цветы, как у дев...

(Бион, 1958: 176)

Таким образом, и необыкновенная бледность Тамерлана у Марло может быт следствием последовательно проводимого уподобления его Ахиллу.

Дж. Каттс даже усматривает в этой параллели определенный парадокс: при всей невероятной мощи Тамерлан Марло, как и Ахилл у античных авторов, наделен отдельными женственными чертами: вьющиеся золотисто-рыжие волосы, белая кожа, оттенок которой подчеркивает и уже упоминавшаяся двусмысленность чтения sinewy / snowy. Исследователь даже склонен трактовать это как своего рода иронию. Хотя Тамерлан подается как героическая фигура, он не совершает боевых подвигов на сцене (только убивает пленных), слишком часто изъясняется как поэт и обвиняет своих сыновей в чрез- 
мерной утонченности, склонности к женщинам, танцам и музыке вместо войны, хотя и сам не лишен той же утонченности (Cutts, 1967: 106-107).

Характерно, что Тамерлан скорбит о наружности сыновей: «Их кудри белы и легки, как пух, / А быть должны как иглы дикобраза, / Черней смолы и жестки, словно сталь!» (Марло, 1961b: 138) - при том, что сам совершенно противоречит этому описанию.

Существует, однако, еще один примечательный аспект, связанный с наружностью Тимура. Хотя европейские историки практически не описывают цвет его кожи, волос и глаз (Гонсалес де Клавихо упоминает глаза лишь в связи со старческой болезнью), в восточных текстах есть более точные описания, и они не противоречат предположительно стилизованным под античность описаниям Марло. Так, Ибн-Арабшах называет его светлокожим, не смуглым; а Альхазен описывает цвет волос как «сумеречный» с отливом в лиловатый, а не черный, и сообщает о его исключительной красоте (Froggatt, 1962: 330). Оба упоминают и необыкновенные сияющие глаза.

Позднейшие историки, в том числе и европейские, даже предполагали, что Тимур мог быть альбиносом. Сколько-нибудь убедительных доказательств этому не существует (ibid.: 333), но и черноволосым Тимур не был. М. М. Герасимов, вскрывавший гробницу Тимура в 1941 г. и проводивший затем антропологический анализ его останков, описывает его волосы как темно-каштановые и рыжие, бороду - как рыже-красноватую, причем это был натуральный оттенок, а не результат покраски хной, как ранее предполагали историки (Герасимов, 1947).

Парадоксальным образом описание Марло оказалось одним из наиболее близких к реальности. Мы не располагаем точными фактами, что какойлибо из текстов восточных историков мог быть доступен Марло. Тем не менее, столь же невозможно опровергнуть утверждение, что Марло мог знать иные источники, кроме достоверно известных нам сейчас, - возможно, восточные полулегендарные варианты биографии Тимура в европейском пересказе, которые уже начинали обретать популярность в Европе в конце XVI в. (Godshalk, 1974: 145).

\section{ЗАКЛЮЧЕНИЕ}

Если упоминание о физическом увечье было осознанно изъято Марло из описания внешности героя, то, возможно, такие необыкновенные черты, как бледность и рыжие волосы, были также осознанно сохранены. Хотя они позволяют провести полную параллель с Ахиллом, кажется преждевременным утверждать, что эти черты полностью заимствованы из античной традиции и неестественно выглядят в антураже средневекового Востока. В образе 
Тамерлана, вполне вероятно, соединены и античная, и средневековая легендарные традиции - из обеих Марло заимствует именно те аспекты, которые необходимы для воплощения на сцене титанической фигуры, отвечающей устремлениям Ренессанса.

\section{СПИСОК ЛИТЕРАТУРЫ}

Бион. (1958) Эпиталамий Ахилла и Дейдамеи // Феокрит, Мосх, Бион. Идиллии и эпиграммы / пер. и комм. М. Е. Грабарь-Пассек. М. : Изд-во АН ССCР. 326 с. С. $175-176$.

Герасимов, М. М. (1947) Портрет Тамерлана (Опыт скульптурного воспроизведения на краниологической основе) // Краткие сообщения о докладах и полевых исследованиях Института истории материальной культуры. Вып. XVII. М. ; Л. : Изд-во АН СССР. 188 с. С. 14-21.

Гомер. (1993) Илиада / пер. с древнегреч. Н. И. Гнедича. М. : Дюна. 432 c.

Гонсалес де Клавихо, Р. (1990) Дневник путешествия в Самарканд ко двору Тимура (1403-1406) / пер. со староиспанского, предисл. и коммент. И. С. Мироковой. М. : Наука. 211 с.

Дадабоев, О. О. (2013) О степени исторической достоверности образа Амира Темура в драме К. Марло «Тамерлан Великий» // Вестник Челябинского государственного университета. № 29 (320). С. 37-39. (Филология. Искусствоведение. Вып. 83).

Литус, В. П. (2014) К 130-летию выхода в свет дневника Руя Гонсалеса де Клавихо «Жизнь и деяния великого Тамерлана с описанием империи и подвластных земель» в переводе на русский язык // Вестник Московского государственного лингвистического университета. Вып. 24 (710). С. 260-265.

Марло, К. (1961а) Тамерлан Великий. Часть I / пер. Э. Л. Линецкой // Марло К. Соч. М. : Гос. изд-во худож. лит-ры. 662 с. С. 43-126.

Марло, К. (1961b) Тамерлан Великий. Часть II / пер. Е. Г. Полонской // Марло К. Соч. М. : Гос. изд-во худож. лит-ры. 662 с. С. 127-210.

Мелехин, А. В. (2019) Тамерлан. М. : АСТ. 351, [1] с.

Стаций, П. П. (2011) Ахиллеида / под общ. ред. А. В. Подосинова. М. : Импэто. 120 с.

Andrea, B. (2010) Persia, Tartaria, and Pamphilia: Ideas of Asia in Mary Wroth's “The Countess of Montgomery's Urania, Part II” // The English Renaissance, Orientalism, and the idea of Asia / ed. by D. Johanyak, W. S. H. Lim. N. Y. : Palgrave Macmillan. vi, 246 p. P. 23-50.

Bodin, J. (1606) The six bookes of a commonweale / written by J. Bodin a famous lawyer, and a man of great experience in matters of state. Out of the French 
and Latine copies, done into English, by Richard Knolles. L. : Impensis G. Bishop [Imprinted by Adam Islip]. [12], 794, [2] p.

Cerasano, S. P. (1994) Tamburlaine and Edward Alleyn's ring // Shakespeare Survey. Vol. 47: Playing places for Shakespeare / ed. by S. Wells. Cambridge : Cambridge University Press. 296 p. P. 171-179.

Cutts, J. (1967) Tamburlaine "as fierce Achilles was” // Comparative Drama. Vol. 1. No. 2 (Summer). P. 105-109. DOI: $10.1353 /$ cdr.1967.0002

Dick, H. G. (1949) "Tamburlaine” sources once more // Studies in Philology. Vol. 46. No. 2 (April). P. 154-166.

Ellis-Fermor, U. (1951) Introduction // Marlowe C. Tamburlaine the Great. 2nd edn. L. : Methuen \& Co. xi, 328 p. P. 1-62.

Froggatt, P. (1962) The albinism of Timur, Zal, and Edward the Confessor // Medical History. Vol. 6. Issue 4. P. 328-342. DOI: 10.1017/s0025727300027666

Godshalk, W. L. (1974) The Marlovian world picture. The Hague : Mouton. 244 p. (Studies in English literature, 93).

Herford, C. H., Wagner, A. (1883) The sources of Marlowe's "Tamburlaine” // The Academy: A weekly review of literature, science, and art. Vol. XXIV: July — December 1883. L. : Printed by Alexander and Shepheard. viii, 442 p. P. 265266.

Marlowe, C. (1951) Tamburlaine the Great. 2nd edn. L. : Methuen \& Co. xi, $328 \mathrm{p}$.

Perondino, P. (1600) Magni Tamerlanis Scytharum imperatoris vita. [Amberg] : Ex typographeio Forsteriano. 66, [2] p.

Seaton, E. (1924) Marlowe's map // Essays and studies by members of the English Association. Vol. 10 / coll. by E. K. Chambers. Oxford : At the Clarendon Press. 144 p. P. 13-35.

Spence, L. (1926) The influence of Marlowe’s sources on “Tamburlaine I” // Modern Philology. Vol. 24. No. 2 (November). P. 181-199. DOI: 10.1086/387637

Thomas, V., Tydeman, W. (1994) Christopher Marlowe: The plays and their sources. L. ; N. Y. : Routledge. xii, 399 p.

Дата поступления: 25.10.2019 г.

\section{REFERENCES}

Bion. (1958) Epitalamii Akhilla i Deidamei [Epithalamium of Achilles and Deidamia]. In: Theocritus, Moschus and Bion. Idillii i epigrammy [Idylls and epigrams] / transl. and comm. by M. E. Grabar-Passek. Moscow : Publ. House of the Academy of Sciences of the USSR. 326 p. Pp. 175-176. (In Russ.). 
Gerasimov, M. M. (1947) Portret Tamerlana (Opyt skul'pturnogo vosproizvedeniia na kraniologicheskoi osnove) [A portrait of Tamerlane (An attempt of sculptural rendition based on craniology)]. In: Kratkie soobshcheniia o dokladakh $i$ polevykh issledovaniiakh Instituta istorii material'noi kul'tury [Concise information on reports and field investigations of the Institute of the History of Material Culture], issue XVII. Moscow ; Leningrad : Publ. House of the Academy of Sciences of the USSR. 188 p. Pp. 14-21. (In Russ.).

Homer. (1993) Iliada [The Iliad] / transl. from ancient Greek by N. I. Gnedich. Moscow : Diuna Publ. 432 p. (In Russ.).

González de Clavijo, R. (1990) Dnevnik puteshestviia v Samarkand ko dvoru Timura (1403-1406) [Embajada a Tamorlán / Embassy to Tamerlane, 1403-1406] / transl. from ancient Spanish, foreword and comm. by I. S. Mirokova. Moscow : Nauka Publ. 211 p. (In Russ.).

Dadaboev, O. O. (2013) O stepeni istoricheskoi dostovernosti obraza Amira Temura v drame K. Marlo «Tamerlan Velikii» [About degree of historical reliability of the image of Amir Temur in C. Marlowe's drama "Tamburlaine the Great"]. Vestnik Cheliabinskogo gosudarstvennogo universiteta, no. 29 (320), pp. 37-39. (Filologiia. Iskusstvovedenie, issue 83). (In Russ.).

Litus, V. P. (2014) K 130-letiiu vykhoda v svet dnevnika Ruia Gonsalesa de Klavikho «Zhizn' i deianiia velikogo Tamerlana s opisaniem imperii i podvlastnykh zemel'»v perevode na russkii iazyk [To the 130th anniversary of publication of Ruy Gonzales de Clavijo’s “Life and Deeds of the Great Tamerlane with Description of the Empire and Subject Lands" in the Russian language]. Vestnik Moskovskogo gosudarstvennogo lingvisticheskogo universiteta, issue 24 (710), pp. 260-265. (In Russ.).

Marlowe, C. (1961a) Tamerlan Velikii. Chast' I [Tamburlaine the Great. Part I] / transl. by E. L. Linetskaia. In: Marlowe, C. Sochineniia [Works]. Moscow : State Publ. of Fiction Literature. 662 p. Pp. 43-126. (In Russ.).

Marlowe, C. (1961b) Tamerlan Velikii. Chast' II [Tamburlaine the Great. Part II] / transl. by E. G. Polonskaia. In: Marlowe, C. Sochineniia [Works]. Moscow : State Publ. of Fiction Literature. 662 p. Pp. 127-210. (In Russ.).

Melekhin, A. V. (2019) Tamerlan [Tamerlane]. Moscow : AST Publ. 351, [1] p. (In Russ.).

Statius, P. P. (2011) Akhilleida [The Achilleid] / ed. by A. V. Podosinov. Moscow : Impeto Publ. 120 p. (In Russ.).

Andrea, B. (2010) Persia, Tartaria, and Pamphilia: Ideas of Asia in Mary Wroth's “The Countess of Montgomery’s Urania, Part II”. In: The English Renaissance, Orientalism, and the idea of Asia / ed. by D. Johanyak, W. S. H. Lim. New York : Palgrave Macmillan. vi, 246 p. Pp. 23-50. 
Bodin, J. (1606) The six bookes of a commonweale / written by J. Bodin a famous lawyer, and a man of great experience in matters of state. Out of the French and Latine copies, done into English, by Richard Knolles. L. : Impensis G. Bishop [Imprinted by Adam Islip]. [12], 794, [2] p.

Cerasano, S. P. (1994) Tamburlaine and Edward Alleyn's ring. In: Shakespeare Survey. Vol. 47: Playing places for Shakespeare / ed. by S. Wells. Cambridge : Cambridge University Press. 296 p. P. 171-179.

Cutts, J. (1967) Tamburlaine “as fierce Achilles was”. Comparative Drama, vol. 1, no. 2 (Summer 1967), pp. 105-109. DOI: 10.1353/cdr.1967.0002

Dick, H. G. (1949) “Tamburlaine” sources once more. Studies in Philology, vol. 46, no. 2 (Apr.), pp. 154-166.

Ellis-Fermor, U. (1951) Introduction. In: Marlowe, C. Tamburlaine the Great. 2nd edn. L. : Methuen \& Co. xi, 328 p. Pp. 1-62.

Froggatt, P. (1962) The albinism of Timur, Zal, and Edward the Confessor. Medical History, vol. 6, issue 4, pp. 328-342. DOI: 10.1017/s0025727300027666

Godshalk, W. L. (1974) The Marlovian world picture. The Hague : Mouton. 244 p. (Studies in English literature, 93).

Herford, C. H. and Wagner, A. (1883) The sources of Marlowe's “Tamburlaine”. In: The Academy: A weekly review of literature, science, and art, vol. XXIV: July — December 1883. London : Printed by Alexander and Shepheard. viii, 442 p. Pp. 265-266.

Marlowe, C. (1951) Tamburlaine the Great. 2nd edn. L. : Methuen \& Co. xi, $328 \mathrm{p}$.

Perondino, P. (1600) Magni Tamerlanis scytharum imperatoris vita [Life of Tamburlaine the Great, Emperor of the Scythians]. [Amberg] : Ex typographeio Forsteriano. 66, [2] p. (In Latin).

Seaton, E. (1924) Marlowe's map. In: Essays and studies by members of the English Association, vol. 10 / coll. by E. K. Chambers. Oxford : At the Clarendon Press. 144 p. Pp. 13-35.

Spence, L. (1926) The influence of Marlowe's sources on "Tamburlaine I". Modern Philology, vol. 24, no. 2 (Nov.), pp. 181-199. DOI: 10.1086/387637

Thomas, V. and Tydeman, W. (1994) Christopher Marlowe: The plays and their sources. London ; New York : Routledge. xii, 399 p.

Submission date: 25.10.2019. 
Шипилова Наталия Витальевна - кандидат филологических наук, старший преподаватель кафедры германской филологии филологического факультета Православного Свято-Тихоновского гуманитарного университета. Адрес: 109651, Россия, г. Москва, ул. Иловайская, д. 9, корп. 2. Тел.: +7 (495) 646-71-38. Эл. адрес: mezora@mail.ru

Shipilova Natalia Vitalyevna, Candidate of Philology, Senior lecturer, Department of Germanic Philology, St. Tikhon's Orthodox University. Postal address: Bldg. 2, 9 Ilovaiskaya St., 109651 Moscow, Russian Federation. Tel.: +7 (495) 646-71-38. E-mail: mezora@mail.ru

Для цุитирования:

Шипилова Н. В. К вопросу о внешности Тамерлана: биографические источники и их интерпретация в пьесах К. Марло [Электронный ресурс] // Горизонты гуманитарного знания. 2019. № 6. C. 60-74. URL: http://journals. mosgu.ru/ggz/article/view/1089 (дата обращения: дд.мм.гггг). DOI: 10.17805/ ggz.2019.6.4 